\title{
Safety and immunogenecity of a live attenuated Rift Valley fever vaccine (CL13T) in camels
}

\author{
S. Daouam ${ }^{1,2^{*}}$, F. Ghzal ${ }^{1}$, Y. Naouli ${ }^{1}$, K. O. Tadlaoui ${ }^{1}$, M. M. Ennaji ${ }^{2}$, C. Oura ${ }^{3}$ and M. EL Harrak'
}

\begin{abstract}
Background: Rift Valley fever is an emerging zoonotic viral disease, enzootic and endemic in Africa and the Arabian Peninsula, which poses a significant threat to both human and animal health. The disease is most severe in ruminants causing abortions in pregnant animals, especially sheep animals and high mortality in young populations. High mortality rates and severe clinical manifestation have also been reported among camel populations in Africa, to attend however none of the currently available live vaccines against RVF have been tested for safety and efficacy in this species. In this study, the safety and efficacy (through a neutralizing antibody response) of the thermostable live attenuated RVF CL13T vaccine were evaluated in camels in two different preliminary experiments involving 16 camels, (that 12 camels and 4 pregnant camels).

Results: The study revealed that the CL13T vaccine was safe to use in camels and no abortions or teratogenic effects were observed. The single dose of the vaccine stimulated a strong and long-lasting neutralizing antibody response for up to 12 months.
\end{abstract}

Conclusion: The presence of neutralization antibodies is likely to correlate with protection; however protection would need to be confirmed by challenge experiments using the virulent RVF virus.

Keywords: Rift Valley fever, Thermostable, Clone 13T vaccine, Camels

\section{Background}

Rift Valley fever (RVF) is a zoonotic viral disease caused by Rift Valley fever virus (RVFV), which is a virus within the genus Phlebovirus and family Bunyaviridae. RVF is enzootic and endemic in Africa, Saudi Arabia and Yemen and poses a significant threat to both human and animal health [1-3]. The disease is most severe in sheep, goats and cattle, causing abortions in pregnant females and high mortality in young animals [4-8].

Vaccination is considered to be the most effective way to prevent and control the expansion of the disease. However, the available attenuated vaccines for RVF cause abortions and teratogenic effects (Smithburn

\footnotetext{
* Correspondence: s.daouam@mci-santeanimale.com

${ }^{1}$ Research and Development Virology, Multi-Chemical Industry, Lot. 157, Z I, Sud-Ouest (ERAC) B.P: 278, Mohammedia 28810, Morocco

${ }^{2}$ Laboratory of Virology, Hygiene \& Microbiology, Faculty of Sciences \&

Technics, University Hassan II Mohammedia-Casablanca, 20650 Mohammedia, Morocco

Full list of author information is available at the end of the article
}

strain vaccine) or are thermolabile (CL13 strain vaccine) $[6,9,10]$. An evaluation of efficacy and safety of the CL13 vaccine in ewes at different stages of pregnancy indicated that the vaccine did not induce clinical manifestation of RVF, such as abortion in pregnant ewes, teratogeny in their offspring or pyrexia in vaccinated animals [11]. Vaccination with CL13 vaccine also prevented clinical RVF following virulent challenge. A recent study carried out by Daouam et al. [12] revealed that the CL13 vaccine strain was unstable in both lyophilized and liquid forms at $22-25{ }^{\circ} \mathrm{C}$ and at $37{ }^{\circ} \mathrm{C}$, which highlight the importance of cold chain when using the CL13 vaccine in endemic tropical countries. In response to this need, the CL13 vaccine strain was made thermostable through three cycles of heating $\left(56{ }^{\circ} \mathrm{C}\right)$ and selection of thermostable particles (12). The thermostable vaccine clone (CL13T) was found to be safe when tested on sheep, goats and cattle with no clinical signs or side effects observed. Neutralizing antibodies were detected in vaccinated animals for a minimum of one year in sheep 
and goats, and for at least 4 months in cattle indicating that the vaccine also provide a good protection [12].

Recent outbreaks of RVF in western Africa have resulted in high mortality and severe clinical signs among dromedary camel populations [13]. Serological surveys in northern and eastern Africa have revealed high percentages of seropositive camels after the occurrence of an outbreak $[14,15]$. Camels are therefore susceptible to RVFV, and are likely to play a role in the epidemiology of the disease and should be included in any vaccination program. There have been no previous reports of camels being vaccinated against RVF, and no RVF vaccines including a thermostablized vaccine have been tested for safety and efficacy in this species. This study therefore was conducted to evaluate the safety and efficacy of the thermostable live attenuated CL13T vaccine in camels.

\section{Methods}

\section{Vaccine (CL13T) production and titration}

The CL13T attenuated virus was propagated and titrated on African Green monkey kidney cells (Vero, ATCC) [9]. The vaccine was formulated by mixing $\mathrm{V} / \mathrm{V}$ the viral suspension with a stabilizer of lyophilisation (4\% peptone, $8 \%$ sucrose and $2 \%$ glutamate). The viral suspension titre is fixed to have a minimum of $10^{6} \mathrm{DICT}_{50}$ per dose. The RVF CL13T vaccine was distributed in glass vials and freeze dried. Before administration, the vaccine was reconstituted by adding a saline solution.

\section{Safety and efficacy testing of the CL13T candidate vaccine in camels}

All experiments involving camels (Camelus Dromedarius) were carried out in accordance with guidelines for the care and handling of experimental animals these animals are dedicated to research and maintained an experimental farm. The animal experiments were approved by the MCI ethics committee in charge of the control and supervision of experiments on animals and the experiments were conducted in high containment level 3 facilities. Sixteen dromedary's camels 2-3 year old, negative for RVFV antibody by the neutralization test were divided in two groups of six and one group of 4 .

In experiment 1: Two groups of 6 camels were vaccinated subcutaneously (SC) with a dose of $10^{6} \mathrm{TCID}_{50}$ of the CL13T vaccine. Camels in group 1 received a single dose of the vaccine and camels of group 2 received a booster dose, four weeks after the first vaccination. The general behavior and rectal temperature of the camels were recorded daily for two weeks after each vaccination as well as observation for local inflammation at the injection site. Sera samples were obtained daily for the first 15 days post-vaccination (PV) and tested for RVFV RNA and infectious virus by quantitative real-time PCR [16] and virus isolation in Vero cells, respectively. Antibody titers were monitored over a 12 months period by virusneutralization (VN) on Vero cell culture as described in the OIE manual (OIE, 2012). VN was performed on 96 wells plates using $100 \mathrm{DL}_{50}$ of the RVFV (CL13) per well with a serial 3 fold dilution of the serum in a 4 wells replicate foe each dilution. After $60 \mathrm{mn}$ of neutralization at $37{ }^{\circ} \mathrm{C}$, the cells suspension was added and the plate incubated 5 days before reading. The neutralizing titre is determined by Reed et Muench method and expressed in $\log 10 / \mathrm{ml}$. Sera were also tested for IgG detection by a competitive ELISA (ID-VET RIFTC-4P).

In experiment 2: a group of 4 pregnant she camels were vaccinated via the $\mathrm{SC}$ route with a $10 \mathrm{X}$ the normal dose $\left(10^{7} \mathrm{TCID}_{50}\right)$ of the CL13T vaccine. Rectal temperatures, appetite and behavior of each animal were documented daily for 1 month and then every month during five months after vaccination until calving for a potential abortions effect and teratogenicity.

\section{Statistical analysis}

The antibody titers detected in the first and second group of camels were compared using the Student $t$ test; with a significance level of $p=0.05$.

\section{Results}

\section{Safety testing of CL13T candidate vaccine in camels}

The C13T vaccine was found to be safe, with no evidence of abortions or teratogenicity among the offsprings of the vaccinated pregnant camels. All camels were healthy and did not have any sign of illness. Normal body temperatures were recorded in the pregnant as well as among the camels in Group 1 and 2 before vaccination and no local reactions were recorded at the injection sites. In the 15 days after vaccination no abnormal behavior was observed in any of the vaccinated animals and their body temperatures remained in the normal range. Very low levels of viral RNA (Cycle Threshold values from 37.6 to 38.6 among a total of 40 cycles) were detected in the blood of 7 of the camels in Groups 1 and 2 during the first 2 weeks following vaccination. However, no infectious virus was isolated from the samples after 2 blind passages on Vero cells. The absence of RVFV in the inoculated cells was confirmed by qPCR.

\section{Serological responses in camels vaccinated with the CL13T candidate vaccine virus}

Neutralizing antibody were recorded in all the vaccinated camels by day $12 \mathrm{PV}$, with peak neutralizing titers of $2.5 \log \mathrm{DN}_{50}$ (equivalent to a serum dilution of 1:500) being observed on day 28 (PV) (Fig. 1). High titers of neutralizing antibody were maintained for a period of 6 months PV, at which time the titers started to wane over the next 6 months, reaching at titer of $0.92 \mathrm{log}$ $\mathrm{DN}_{50}$ (equivalent to a serum dilution of $1: 10$ ) at twelve 


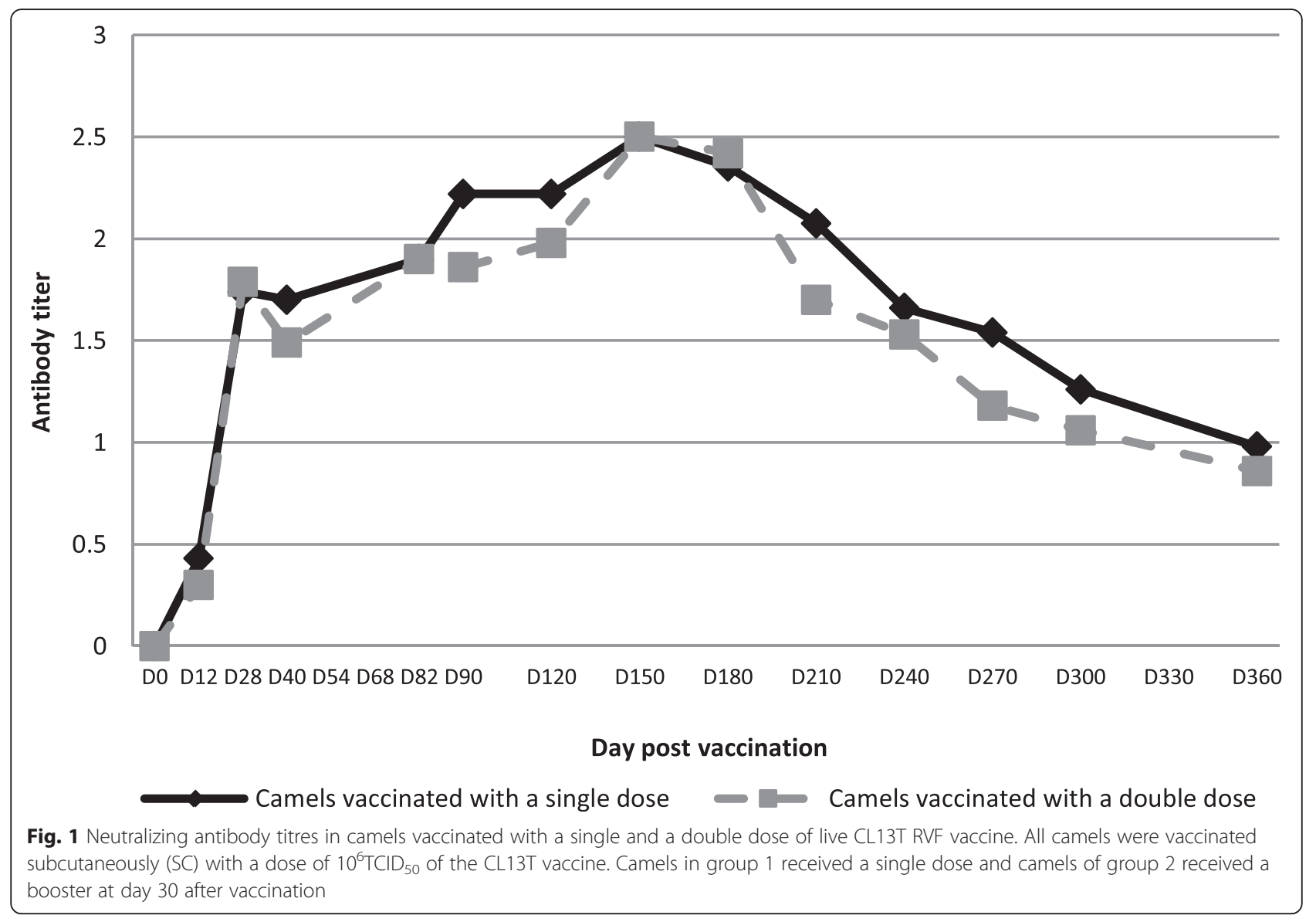

months post-vaccination (Fig. 1). Similar antibody titers were detected in camels vaccinated once (group 1) and twice (group 2), showing that there was no significant increase in neutralizing antibody titers through the administration of a booster dose of the vaccine.

Significant differences $(\mathrm{p}<0.05)$ in antibody titers were observed in the sera samples from camels tested by $\mathrm{VN}$ as compared to those tested by cELISA. Antibody titers measured by the two tests (VN and cELISA) remained similar for the first 3 months post-vaccination and then diverged to attain titers that were significantly different (Fig. 2). Results revealed a reduced sensitivity of the cELISA compared to the $\mathrm{VN}$ test for the detection of RVFV antibody (Fig. 2). It is important to note however that the cELISA kit used in this study has only been validated for use in ruminants. Thus, results indicate that this cELISA may not be optimized for use in camels and that the sensitivity of the assay may need to be improved before it can be recommended for routine diagnosis or for vaccination monitoring in camels.

\section{Discussion}

This study reveals that camels mounted a strong and longlasting neutralizing antibody response when vaccinated with a single dose of the live CL13T RVF vaccine and that the vaccine is safe to use, producing no significant sideeffects in the vaccinated animals. The neutralizing antibody response was similar to that observed in small ruminants and cattle after vaccination with the live RVF clone 13 vaccine $[17,18]$.

This is the first report that evaluates the safety and efficacy of a live attenuated thermostabilized RVF vaccine in camels. To be sure that this vaccine protects camels against RVF, challenge studies would need to be carried out. However in the case of RVF, neutralizing antibodies are known to be reliable predictor of protection after vaccination $[17,19]$. The high levels of neutralizing antibodies observed in the vaccinated camels may indicate therefore that the CL13T vaccine is likely to be protective in camels for up to 12 months.

It is highly recommended to vaccinate livestock to prevent the occurrence of disease in susceptible animals and if possible virus amplifying hosts, in order to break the epidemiological transmission cycle. With the high densities of dromedary camels in many areas where RVF is present, it is extremely important to be able to protect camels, as well as other susceptible species. 


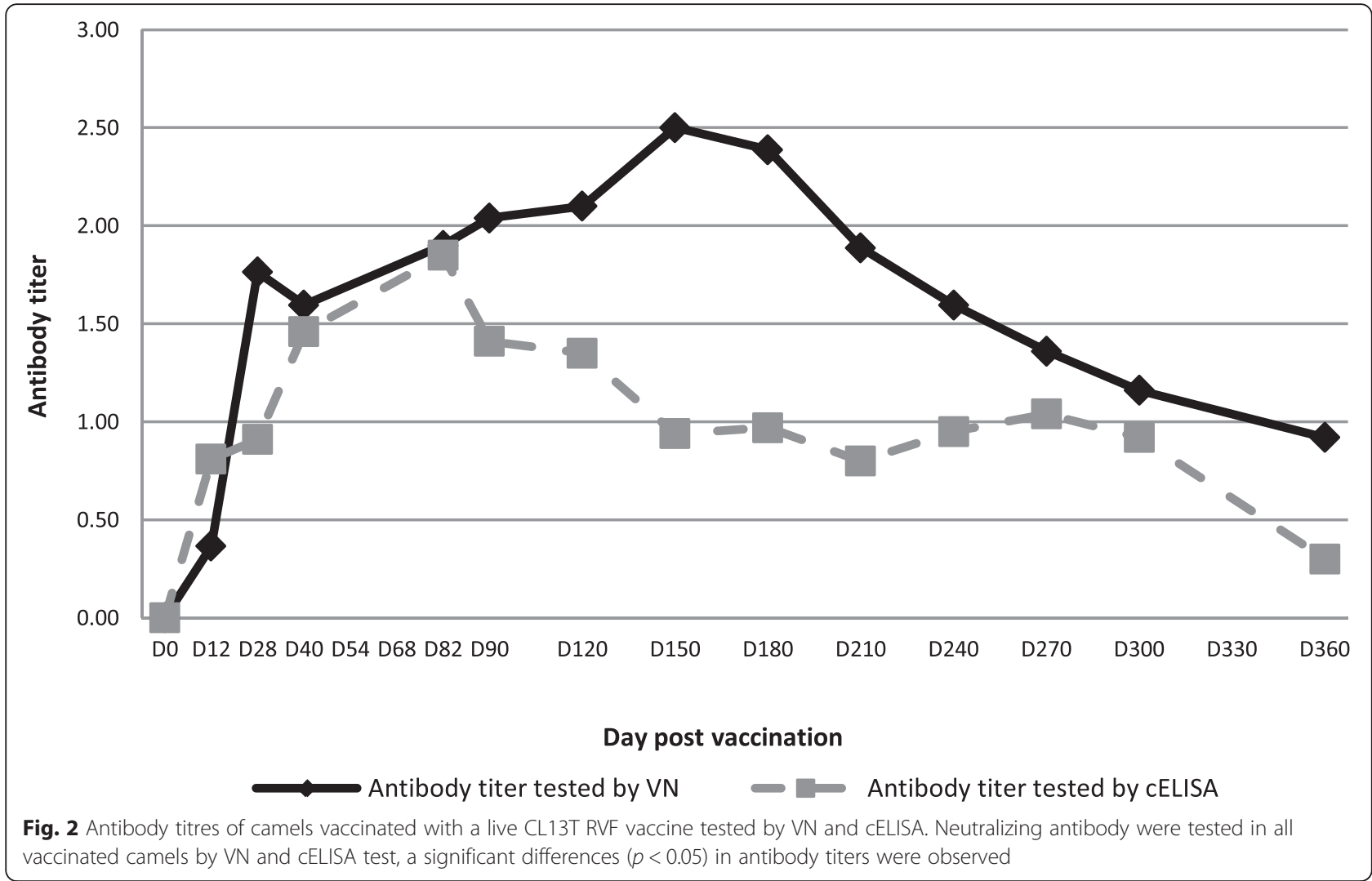

This is the first study that has evaluated the safety and immunogenicity of a live attenuated RVF vaccine in camels. A recent study, reported camel vaccination with a recombinant adenovirus encoding RVFV envelope glycoprotein. A lower antibody neutralizing titre was observed in camels comparatively to other species (sheep, goats and cattle) with a dose of $10^{9}$ injected intramuscularly in the presence of an adjuvant [19]. No challenge was carried out for the protection testing.

\section{Conclusions}

In our study, the obtained antibody response in vaccinated camels was similar to that registered in sheep and better than cattle response with a dose of $10^{6}$ only, injected by $\mathrm{S} / \mathrm{C}$ route. Although this is a preliminary study, the presence of neutralization antibodies is likely to correlate with protection. To be noted that RVF protection of camels has never been tested by experimental infection and no challenge model has been developed for camels.

In summary, the study showed that the CL13T live attenuated vaccine is safe to use in camels and that a single dose of the vaccine stimulated strong and long-lasting neutralizing antibody response for up to 12 months. In the absence of any tested live vaccine for camels, the CL13T vaccine could be considered for camel protection against RVF after a field trial that include sufficient number of animals under the normal living conditions.

\section{Abbreviation}

CL13, clone 13; CL13T, clone 13 thermostable; PV, post-vaccination; RVF, Rift Valley fever; RVFV, Rift Valley fever virus; SC, subcutaneously; Vero, African Green monkey kidney cells; VN, virus-neutralization

\section{Acknowledgements}

All the authors have seen and approved the content and have contributed significantly to the work.

Funding

No funding was obtained for this study.

Availability of data and materials

The data and materials are available in the main manuscript.

\section{Authors' contributions}

$\mathrm{SD}$ and ME planned and conceived the experiments; KT participated in the design and the follow up of the study; FG performed the safety and the potency testing, YN carried out the Elisa test; SD carried out other laboratory works; SD, ME, MME and CO analyzed the data and wrote the manuscript. All authors read and approved the final manuscript.

\section{Competing interests}

The authors declare that they have no competing interests.

\section{Consent for publication}

Not applicable.

\section{Ethics approval and consent to participate}

This study was performed in accordance with the international guidelines for care and handling of experimental animals, as the protocol has been 
submitted and approved by the Internal Ethic Committee "The internal ethic committee for animal experiment, $\mathrm{MCl}$ santé animale".

\section{Author details}

'Research and Development Virology, Multi-Chemical Industry, Lot. 157, Z I, Sud-Ouest (ERAC) B.P: 278, Mohammedia 28810, Morocco. ${ }^{2}$ Laboratory of Virology, Hygiene \& Microbiology, Faculty of Sciences \& Technics, University Hassan II Mohammedia-Casablanca, 20650 Mohammedia, Morocco. ${ }^{3}$ School of Veterinary Medicine, University of the West Indies, St. Augustine, Trinidad and Tobago

Received: 17 February 2016 Accepted: 16 July 2016

Published online: 26 July 2016

\section{References}

1. Meegan JM. The Rift Valley fever epizootic in Egypt 1977-78. 1. Description of the epizzotic and virological studies. Trans R Soc Trop Med Hyg. 1979; 73(6):618-23.

2. Balkhy HH, Memish ZA. Rift Valley fever: an uninvited zoonosis in the Arabian peninsula. Int J Antimicrob Agents. 2003;21(2):153-7.

3. Sissoko D, Giry C, Gabrie P, Tarantola A, Pettinelli F, Collet L, D'Ortenzio E, Renault P, Pierre V. Rift Valley Fever, Mayotte, 2007-2008. Emerg Infect Dis. 2009;15(4):568-70.

4. Easterday BC, Mc GM, Rooney JR, Murphy LC. The pathogenesis of Rift Valley fever in lambs. Am J Vet Res. 1962;23:470-9.

5. Coetzer JA. The pathology of Rift Valley fever. I. Lesions occurring in natural cases in new-born lambs. Onderstepoort J Vet Res. 1977;44(4):205-11.

6. Coetzer JA, Barnard BJ. Hydrops amnii in sheep associated with hydranencephaly and arthrogryposis with wesselsbron disease and rift valley fever viruses as aetiological agents. Onderstepoort J Vet Res. 1977; 44(2):119-26.

7. Flick R, Bouloy M. Rift Valley fever virus. Curr Mol Med. 2005;5(8):827-34.

8. Pepin M, Bouloy M, Bird BH, Kemp A, Paweska J. Rift Valley fever virus(Bunyaviridae: Phlebovirus): an update on pathogenesis, molecular epidemiology, vectors, diagnostics and prevention. Vet Res. 2010;41(6):61.

9. Daouam S, Fakri FZ, Ennaji MM, El Arkam A, Tadlaoui KO, Oura C, Elharrak M. Heat stability of the Rift Valley Fever Virus Clone 13 live vaccines. Trials Vaccinol. 2014;3:61-4.

10. Khafagy HA, Ebied MH, Abdelwahab MG, Saad MA. Clinical and immunological studies on live attenuated Rift Valley Fever vaccine. N Y Sci J. 2013;6:12-7.

11. Kaschula VR. The propagation and modification of strains of Rift Valley fever viruses in embryonated eggs and their use as immunizing agents for domestic ruminants. South Africa: Thesis Doctor of Veterinary Science, University of Pretoria; 1953.

12. Daouam SGF, EL Arkam A, Naouli Y, Jazouli M, Ennaji MM, Tadlaoui KO, Oura C, Elharrak M. Evaluation of the safety and efficacy of a live attenuated thermostable Rift Valley fever vaccine in Sheep, Goats and Cattle. J Vaccines Vaccin. 2015;6:295. doi:2157-7560.1000295.

13. El Mamy AB, Baba MO, Barry Y, Isselmou K, Dia ML, El Kory MO, Diop M, Lo MM, Thiongane Y, Bengoumi M, et al. Unexpected Rift Valley fever outbreak, northern Mauritania. Emerg Infect Dis. 2011;17(10):1894-6.

14. El-Harrak M, Martín-Folgar R, Llorente F, Fernández-Pacheco P, Brun A, Figuerola J, Jiménez-Clavero MÁ. Rift Valley and West Nile Virus Antibodies in Camels. North Afr Emerg Infect Dis. 2011;17(12):2372-4.

15. Swai ES, Sindato C. Seroprevalence of Rift Valley fever virus infection in camels (dromedaries) in northern Tanzania. Trop Anim Health Prod. 2015; 47(2):347-52.

16. Anyangu AS, Gould LH, Sharif SK, Nguku PM, Omolo JO, Mutonga D, Rao CY, Lederman ER, Schnabel D, Paweska JT, et al. Risk factors for severe Rift Valley fever infection in Kenya, 2007. Am J Trop Med Hyg. 2010;83(2 Suppl):14-21.

17. Dungu B, Louw I, Lubisi A, Hunter P, von Teichman BF, Bouloy M. Evaluation of the efficacy and safety of the Rift Valley Fever Clone 13 vaccine in sheep. Vaccine. 2010;28(29):4581-7.

18. von Teichman B, Engelbrecht A, Zulu G, Dungu B, Pardini A, Bouloy M. Safety and efficacy of Rift Valley fever Smithburn and Clone 13 vaccines in calves. Vaccine. 2011;29(34):5771-7.

19. Warimwe GM, Gesharisha J, Carr BV, Otieno S, Otingah K, Wright D, Charleston B, Okoth E, Elena LG, Lorenzo G, et al. Chimpanzee Adenovirus vaccine provides multispecies protection against Rift Valley fever. Sci Rep. 2016;6:20617.

\section{Submit your next manuscript to BioMed Central and we will help you at every step:}

- We accept pre-submission inquiries

- Our selector tool helps you to find the most relevant journal

- We provide round the clock customer support

- Convenient online submission

- Thorough peer review

- Inclusion in PubMed and all major indexing services

- Maximum visibility for your research

Submit your manuscript at www.biomedcentral.com/submit 